\title{
Selection of Sustainable Supplementary Concrete Materials Using OSM-AHP-TOPSIS Approach
}

\author{
Mohd. Ahmed (D, ${ }^{1}$ M. N. Qureshi, ${ }^{2}$ Javed Mallick, ${ }^{1}$ and Nabil Ben Kahla ${ }^{1}$ \\ ${ }^{1}$ Civil Engineering Department, Engineering Faculty, King Khalid University, Abha, Saudi Arabia \\ ${ }^{2}$ Indusrial Engineering Department, Engineering Faculty, King Khalid University, Abha, Saudi Arabia \\ Correspondence should be addressed to Mohd. Ahmed; moahmedkku@gmail.com
}

Received 2 October 2018; Revised 6 April 2019; Accepted 13 May 2019; Published 29 May 2019

Academic Editor: Fernando Lusquiños

Copyright (C) 2019 Mohd. Ahmed et al. This is an open access article distributed under the Creative Commons Attribution License, which permits unrestricted use, distribution, and reproduction in any medium, provided the original work is properly cited.

\begin{abstract}
Due to resource scarcity, environmental impact, and socioeconomic constraints, sustainable criteria should be given prime importance in the construction industry. The sustainability in concrete can be attained using supplementary materials. The numbers of supplementary concrete materials (SCMs) are available ranging from industries by-products, agro-products, waste product, and newly engineered materials. The selection of the supplementary materials is challenging due to the wide range of environmental, technical, and economic constraints. The paper proposes a decision support framework considering technical, environmental, social, and economic sustainability criteria for ranking of concrete supplementary material. The decision framework includes the optimal scoring method- (OSM-) based shortlisting of supplementary materials, with technical and cost characteristics, and subsequent prioritizing material according to sustainable potentiality order using AHP-TOPSIS. The stability of the ranking of sustainable concrete supplementary materials has been verified using sensitivity analysis. The present study develops decision support framework by employing technical characteristics of the most technically sound material used as concrete material. The technical, environmental, and socioeconomic sustainable performance indicators have considered its selection to obtain much needed sustainability and to boost the eco-friendly environment. From the proposed MCDM framework, it is found that engineered siliceous materials and agriculture-based industrial waste products as SCMs will prove to be most sustainable in the construction industry.
\end{abstract}

\section{Introduction}

The concrete used in the construction industry essentially consists of aggregate and cementitious material. The addition of supplementary materials to concrete can extend concrete life and reduce concrete production cost. The selection of construction material to have the best all-round performance is a complex process. Zavadskas et al. [1] also considered the selection of construction materials as vital since it contributes a significant portion of the total cost of the structure. The cement manufacturing process requires high energy and higher resources [2]. The costly cement utilization in the construction industry may be reduced to control its impact on the costs and the environment. Cement production emits approximately $5 \%$ of global carbon dioxide $\left(\mathrm{CO}_{2}\right)$ and $5 \%$ of global energy consumption [3].
The construction industry should prefer the use of sustainable eco-friendly materials, in order to be societally concerned, resource and energy efficient, and environment-friendly. The sustainable development is basically required to manufacture the product economically and control the harmful effect of construction materials on the society and environment. Claisse et al. [4] have provided an account of research on new ingredients to concrete. The multicriteria decision-making (MCDM) approach has been widely used in the construction industry for the selection of alternatives for construction plans, methods, activities, and materials, in relation to sustainable performance. The environmental aspects, social and economic issues based selection model is developed by Abeysundara et al. [5] for sustainable building materials, and they concluded that environmental criteria have to be 
preferred over the social and economic criteria for sustainable building construction. The basic characteristics of the concrete supplementary materials and their role in concrete are well documented in the literature [6]. A sustainable scoring system model is developed by Bakhoum and Brown [7] to evaluate the structural materials considering material sustainable measurement scales. Application of analytic hierarchy process (AHP), technique for the order of preference by similarity to ideal solution (TOPSIS) along with entropy method, is employed for the sustainable ranking of the structural material [8]. An AHP methodology is used in selecting an optimal patching material for repairing the concrete by successfully adhering to physical and chemical performance [9]. Akadiri et al. [10] employed Fuzzy AHP techniques to prioritize building materials. Later on, Ardeshir et al. [11] used them to select the potential sites for bridge construction by using geographical information system (GIS). Arroyo et al. [12] selected the sustainable building material by the Choosing by Advantages (CBA) decision-making procedure. The sustainability indicators for residential building relating to environmental, economic, and social performances are ranked by Abdul-Rahman et al. [13]. Ahmed et al. [14] employed a combined AHP-TOPSIS methodology in designing concrete mixtures for high performance. Favi et al. [15] proposed a new approach to address uncertainty and sensitivity analysis in life-cycle assessment (LCA) to support the decision-making process in building retrofit measures. The decision-making model is based on material selection, maintenance, and use.

It has been evident that the selection of the available materials for the construction sector should be based on the fulfillment of sustainability objectives that provide a healthy and green environment and offer the solution to socioeconomic issues. On reviewing the literature, it has been learned that the use of MCDM for the selection of sustainable concrete materials in the construction industry is limited. In the present study, the combined approach of OSM-AHP-TOPSIS has been implemented for the ranking of supplementary construction materials using known technical characteristics and sustainability performance indicators.

\section{Selection of Sustainability Evaluation Indicators}

The selection of sustainability performance indicators, for instance, technical, social, environmental, and economical, in evaluating sustainability of construction material is found enormously in the literature (technical indicators: [3, 16-19]; environmental indicators: [20-24]; socioeconomic indicators: [7, 25-28]. The five decision-makers having vast working experience of more than five years constituted the team. Apart from their own expertise, they also considered the views of construction material experts, environmentalists, geotechnical experts, and government units to provide more robustness to the final output of sustainable materials selection. The final list of developed sustainability evaluation contains 20 indicators as shown in Table 1.
TABLE 1: Sustainability indicators along with subcriteria for selection of supplementary concrete materials.

\begin{tabular}{lc}
\hline Criteria & Subcriteria \\
\hline & Support to concrete curing system $\left(C_{11}\right)$ \\
& Support to concrete compaction system $\left(C_{12}\right)$ \\
& Support to cohesiveness of concrete mix $\left(C_{13}\right)$ \\
& Support to consistency of concrete mix $\left(C_{14}\right)$ \\
& Comply strength requirement of concrete mix \\
Technical & $\left(C_{15}\right)$ \\
$\left(C_{1}\right)$ & Comply durability requirements of concrete mix \\
& $\left(C_{16}\right)$ \\
& Relative proportion of concrete components \\
& $\left(C_{17}\right)$ \\
& Supplementary material availability $\left(C_{18}\right)$ \\
\hline Environmental & Energy conservation $\left(C_{21}\right)$ \\
$\left(C_{2}\right)$ & Concrete material conservation $\left(C_{22}\right)$ \\
& Waste material utilization $\left(C_{23}\right)$ \\
& Conformation to environmental standards $\left(C_{24}\right)$ \\
& Reduction in carbon foot print $\left(C_{25}\right)$ \\
Social $\left(C_{3}\right)$ & Resistance to extreme exposure conditions $\left(C_{26}\right)$ \\
\hline & Waste material cleaning $\left(C_{31}\right)$ \\
& Public welfare and safety $\left(C_{32}\right)$ \\
& Increased employment $\left(C_{33}\right)$ \\
\hline Economic $\left(C_{4}\right)$ & Concrete production cost $\left(C_{41}\right)$ \\
& Supplementary material transportation cost \\
& $\left(C_{42}\right)$ \\
& Life-long maintenance cost $\left(C_{43}\right)$ \\
\hline
\end{tabular}

\section{Optimal Scoring Method (OSM)}

The optimal scoring method (OSM) is a framework for ranking materials for a specific cause [29]. The OSM helps the decision-making team to prioritize the candidate material which is part of a set of alternative materials as $I$ based on a set of assessment criteria J. Moreover, a set of " $R$ " rules may be constructed in order to obtain decisions for fixing the importance based on the evaluation criteria. The rules pertaining to the judgment is at the discretion of the decision makers. Various criteria have been used in comparing the materials; as an instance, if criteria $A_{i}, B_{i}$, $C_{i}, \ldots, G_{i}$ are considered for evaluating the material, the criteria importance of $A_{i}, B_{i}, C_{i}, \ldots, G_{i}$ is maintained in the same order. The other rule may take care of the preferred weights of the criteria; for instance, $A_{i}$ criterion has twice the importance in comparison to another criterion $B_{i}$ and so on. Another rule may take in to account the cumulative significance of combined criteria of $A_{i}, B_{i}, C_{i}$, in comparison to another set of criteria $D_{i}, E_{i}, F_{i}$, etc. As given in Sefair et al. [29], "Parameter vectors $l \triangleq\left[l_{j}\right]$ and $u \triangleq\left[u_{j}\right]$ specify minimum and maximum bounds on the importance for each evaluation criterion $j \in \mathbf{J}$ ". "The matrix of realizations of the evaluation criteria is defined by $D \triangleq$ $\left[\overline{d_{i j}} \in \mathfrak{R}\right](i \in \mathbf{I}, j \in \mathbf{J})$ where $d_{i j}$ refers to the assessment of criteria $j$ for material $i$ ". "To convert the evaluation criteria to commensurable units, a matrix of normalized values is defined by $\bar{D} \triangleq\left[\overline{d_{i j}} \in \mathfrak{R}\right](i \in \mathbf{I}, j \in \mathbf{J})$ ".

The OSM gives a dimensionless score vector, $\mathbf{Z} \triangleq\left[\mathbf{Z}_{\boldsymbol{i}}\right]$. It provides one score per material by assigning the best weights for each criterion $\mathbf{w} \triangleq\left[\mathbf{w}_{\mathbf{i}}\right]$. The assigned weight ranges from 0 
to $100 \%$ in line with the relative importance of each criterion. If the obtained weight of a selected criterion is more than another criterion, it means that the selected criterion holds more importance in decision making. Thus, the OSM approach helps in assigning the maximum possible score while obeying the set of rules for selecting the criterion importance.

\section{Methodology}

Various MCDM techniques have been developed in order to measure and compare criteria, alternatives, and goals in given conditions. From the available MCDM techniques, a combined AHP [30] and TOPSIS [31] approach is applied in selecting supplementary construction material with sustainable characteristics. The supplementary concrete materials are shortlisted to have the best technically and economically sound material from the available supplementary materials having known technical characteristics using the optimal scoring method (OSM). The characteristics considered for OSM that influence the blended concrete most are the percentage of $\mathrm{CaO}$, surface area, compressive strength, chloride resistance, and the cost of the material. The highest scoring materials are further ranked for sustainability through the integrated AHP-TOPSIS approach. The aim is to develop a decision support framework in terms of whether or not the materials fulfil the objectives of technically sound as well as sustainable-performance materials. Problem formulation determines relevant attributes, criteria, and indicators that contribute to the problems. The sustainability of the supplementary concrete material is assessed considering the achievement of eight technical, six environmental, three social, and three economic criteria. The adopted technical sustainability indicator for concrete supplementary material includes the relative proportion of concrete components, material availability, support of supplementary material to concrete curing system, compaction system, cohesiveness, and consistency of concrete mix and effect of the addition of supplementary material on the strength and durability requirement of concrete.

The sustainability indicators for the selection of concrete supplementary material to achieve the environmental objectives are adopted as energy conservation, concrete material conservation, waste material utilization, conformation to environmental standards, reduction in carbon footprint, and resistance to extreme exposure conditions. The sustainability indicators for concrete supplementary material to fulfil the socioeconomic goals are framed as waste material cleaning, public welfare and safety, increased employment, concrete production cost, supplementary material transportation cost, and life-long maintenance cost. The selection process calculates the importance weight of the shortlisted supplementary material to rank supplementary material for sustainability. The proposed hybrid AHP-TOPSIS-based decision support framework along with OSM methodology for selection of the technically sound sustainable supplementary concrete material is depicted in Figure 1. The proposed framework to select the potential sustainable supplementary material includes seven steps which are shown in Figure 1.
4.1. Developing the Goal Criteria and Shortlisting of Supplementary Concrete Material Using OSM. In this step, the goal criteria (sustainable performance-based ranking of supplementary concrete material) are identified in accordance with the decision makers. The number of industry- and agro-based by-products and other engineered materials may be considered as supplementary material in concrete manufacturing. The ten most common supplementary materials are, namely, nanocement; nanoparticles of supplementary siliceous material; pozzolanic materials, namely, natural pozzolana; metakaolin; waste siliceous material, namely, fly ash; silica fume; blast furnace slag; rice husk ash; limestone; and recycled material, namely, waste glass and recycled aggregate. The OSM approach [29] is applied to shortlist the supplementary materials based on scoring rank calculated from known technical characteristics. Table 2 shows the OSM score using the Cuadrado et al. [28] approach. The order of the material selected starting from the highest score is as nanocement, nanoparticles of siliceous material, blast furnace slag, fly ash, silica fume, metakaolin, waste glass, natural pozzolana, limestone, rice husk ash, and recycled aggregate. First, five maximum optimal scoring materials are taken for further sustainability ranking using the hybrid AHP-TOPSIS-based methodology. The nanoparticle of supplementary siliceous material is preferred over the nanocement being the supplementary material. The materials considered for sustainability ranking are nanoparticles of supplementary siliceous material (NPSSM), blast furnace slag (BFS), fly ash (FA), metakaolin $(\mathrm{MN})$, and silica fume (SF).

\subsection{Decision Matrix Normalizing to Calculate the Matrix} Weights Using AHP. The supplementary construction material is subjected to criteria assessment, i.e., the achievement of eight technical, six environmental, four social, and three economical subcriteria as mentioned above. The pairwise comparisons of criteria (sustainability criteria), subcriteria (sustainability indicators), and the alternative (supplementary concrete materials) are done using the equations given by Saaty's scale [30]. The matrix for a pairwise comparison of the main criteria is then used to normalize the decision matrix and calculate the matrix weights. The sustainability criteria are compared using a pairwise comparison method and subsequently, the alternative supplementary materials along with their weights are given in Tables 3 and 4 .

\subsection{Consistency Checking of Each Pairwise Comparison} Matrix. The consistency of decision-making may be checked by the consistency check method proposed by Saaty [30]. It contains the estimation of the maximum eigenvalue $\left(\lambda_{\max }\right)$, consistency index (CI), and consistency ratio (CR) of each aggregate matrix and pairwise comparison matrix. The estimated values are found to be under $10 \%$, thus confirming the satisfactory degree of consistency.

4.4. Calculate the Relative Weights of the Alternatives (Supplementary Materials) with respect to Each Weight of Subcriterion (Sustainability Indicators). The relative weights of 


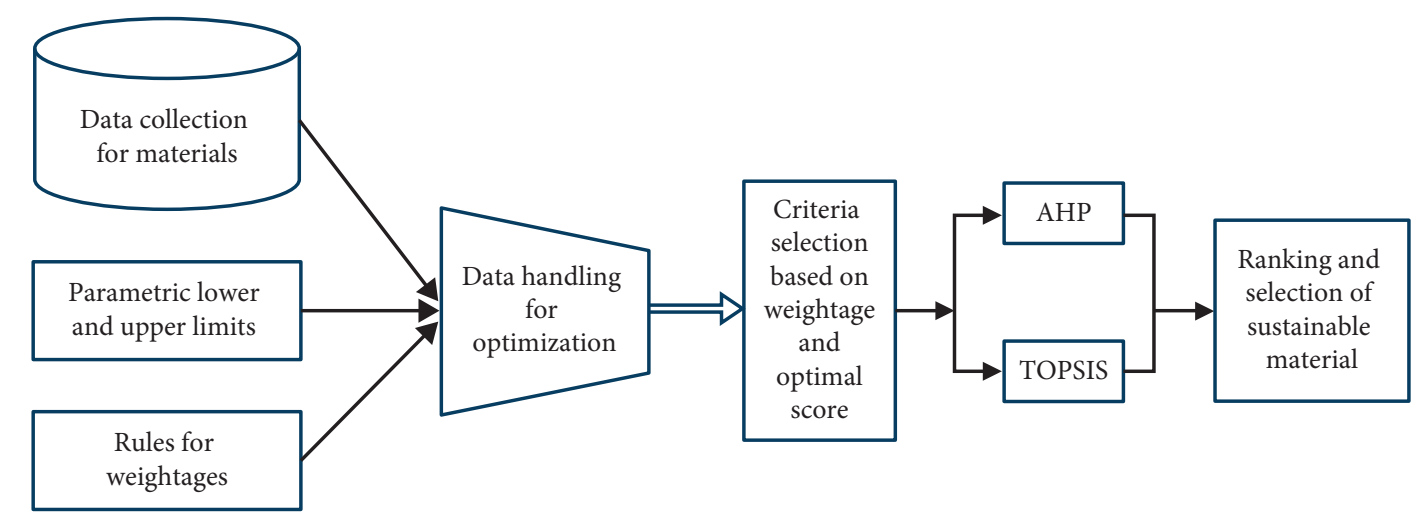

FIGURE 1: OSM and AHP-TOPSIS-based framework for selection of sustainable supplementary concrete material.

TABLE 2: Candidate materials for shortlisting of supplementary concrete material.

\begin{tabular}{|c|c|c|c|c|c|c|}
\hline Supplementary material & $\%$ of $\mathrm{CaO}^{\mathrm{a}}$ & Surface area ${ }^{a}$ & Concrete strength $^{\mathrm{b}}$ & Chloride resistance $^{\mathrm{b}}$ & $\operatorname{Cost}^{\mathrm{c}}$ & Optimal Score \\
\hline Limestone & $40-55$ & $200-400$ & 1 & 1 & 3 & 0.265 \\
\hline Blast furnace slag & $30-45$ & $400-600$ & 2 & 3 & 3 & 0.381 \\
\hline Metakaolin & $0.5-2$ & $10,000-25,000$ & 4 & 2 & 3 & 0.308 \\
\hline Fly ash & $10-35$ & $300-500$ & 2 & 1 & 5 & 0.328 \\
\hline Rise husk ash & $0.5-1$ & $10,000-18,000$ & 2 & 1 & 4 & 0.206 \\
\hline Silica fume & $0.5-1$ & $15,000-30,000$ & 4 & 4 & 1 & 0.308 \\
\hline Nanocement & $50-65$ & $1000,000-800,000$ & 5 & 5 & 1 & 0.800 \\
\hline Nanoparticles supp. material & $1-10$ & $900,000-500,000$ & 4 & 5 & 1 & 0.525 \\
\hline Recycled aggregate & $1-3$ & 0.1 & 1 & 1 & 3 & 0.107 \\
\hline Waste glass & $5-10$ & $200-400$ & 1 & 2 & 5 & 0.276 \\
\hline Natural pozolona & $10-30$ & $300-400$ & 1 & 1 & 5 & 0.270 \\
\hline OSM weight & 0.2 & 0.2 & 0.2 & 0.2 & 0.2 & - \\
\hline
\end{tabular}

${ }^{a}$ Quantitative values normalized for weights. ${ }^{b} 5$, excellent; 4 , very good; 3 , good; 2 , fair; 1 , poor. ${ }^{c} 5$, very inexpensive; 4 , inexpensive; 3 , moderate price; 2 , expensive; 1 , very expensive.

TABLE 3: Pairwise comparison of sustainability criteria for selection of concrete supplementary material.

\begin{tabular}{|c|c|c|c|c|c|}
\hline Criteria & Technical & Environmental & Social & Economic & Weights \\
\hline Technical $\left(C_{1}\right)$ & 1.00 & 0.38 & 2.29 & 2.29 & 0.2655 \\
\hline Environmental $\left(C_{2}\right)$ & 2.62 & 1.00 & 2.62 & 2.29 & 0.4364 \\
\hline Social $\left(C_{3}\right)$ & 0.44 & 0.38 & 1.00 & 0.50 & 0.1198 \\
\hline \multirow[t]{2}{*}{ Economic $\left(C_{4}\right)$} & 0.44 & 0.44 & 2.00 & 1.00 & 0.1783 \\
\hline & \multicolumn{2}{|c|}{$\lambda_{\max }=4.1531, \mathrm{CI}=0.051$} & \multicolumn{2}{|c|}{$\mathrm{RI}=0.9, \mathrm{CR}=0.0567$} & \\
\hline
\end{tabular}

TABLE 4: Pairwise comparison of OSM-ranked concrete supplementary material.

\begin{tabular}{lcccccc}
\hline Material & BFS & MN & FA & SF & NPSSM & Weights \\
\hline BFS $\left(A_{1}\right)$ & 1.00 & 1.00 & 0.50 & 2.00 & 1.00 & 0.1725 \\
MN $\left(A_{2}\right)$ & 1.00 & 1.00 & 0.50 & 2.00 & 1.00 & 0.1725 \\
FA $\left(A_{3}\right)$ & 2.00 & 2.00 & 1.00 & 7.00 & 3.00 & 0.4185 \\
SF $\left(A_{4}\right)$ & 0.50 & 0.50 & 0.14 & 1.00 & 0.50 & 0.0776 \\
NPSSM $\left(A_{5}\right)$ & 1.00 & 1.00 & 0.33 & 2.00 & 1.00 & 0.1590 \\
TOTAL & 5.500 & 5.500 & 2.476 & 14.000 & 6.500 & 1.0000 \\
& $\lambda_{\max }=5.0393$, & RI $=1.12, \mathrm{CR}=0.0088$ \\
\hline
\end{tabular}

the four objective criteria, namely, technical, environmental, social, and economic criteria and subcriteria (sustainable indicators), are obtained from the aggregated values using the eigenvector method [30]. Later on, the weights of the five alternatives with respect to subcriteria (sustainable indicators) are calculated. The relative weights of alternatives, five sustainable supplementary materials, with respect to the weight of each twenty sustainable indicators are given in Table 5.

4.5. Applying TOPSIS Methodology by Normalizing the Decision Matrix. The normalized decision matrix and weighted normalized decision matrix may be obtained by using the TOPSIS methodology [31]. Tables 6 and 7 show the obtained normalized decision matrix and weighted normalized decision matrix.

4.6. Calculate the Positive Ideal and Negative Ideal Solutions along with the Separation Measures. The positive ideal solution $\left(A^{*}\right)$ and negative ideal solution $\left(A^{-}\right)$may be obtained. The separation distances of each alternative from the 


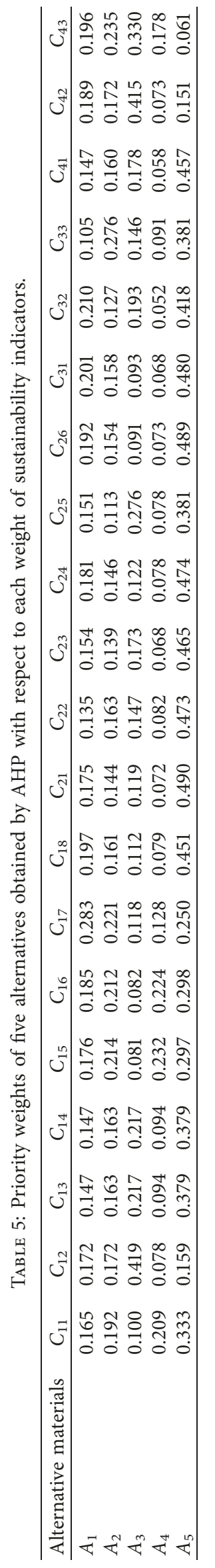




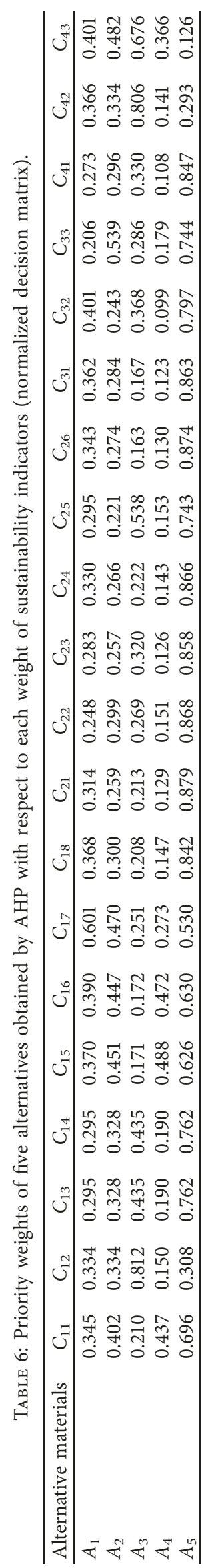




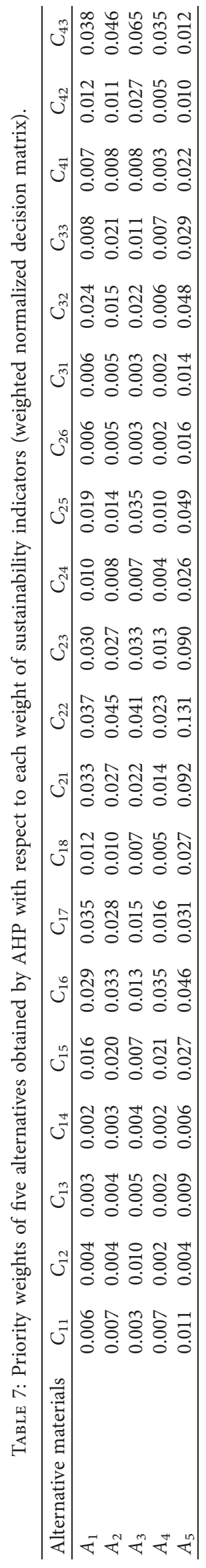


positive and negative ideal solution are calculated, and the positive ideal solution $\left(D_{j}^{*}\right)$ and negative ideal solution $\left(D_{j}^{-}\right)$ values are shown in Table 8.

\subsection{Relative Closeness Calculation to the Ideal Solution and} Ranking. The relative closeness also termed as closeness coefficient (CC) is the determination of closeness of each alternative supplementary concrete material to the ideal solution. The combined OSM-AHP-TOPSIS approach thus provides the ranking of alternative supplementary concrete materials; the same is depicted in Table 9.

\section{Sensitivity Analysis}

The sensitivity analysis demonstrates the influence and stability of objectives criterion's weight (sustainability criterion), obtained by the AHP approach, on alternatives (supplementary concrete materials) selection. For sensitivity analysis, each criterion's weight is interchanged with another criterion's weight. In this study, nine conditions are analyzed for sensitivity. For each condition, the closeness coefficient to the ideal solution $\mathbf{C}_{\mathbf{j}}^{*}$ is computed. The output obtained by sensitivity analysis is shown in Table 10 and Figure 2. Table 10 expresses the original results of the combined AHPTOPSIS methodology using the first condition. It also indicates that the selection of supplementary concrete materials process should give prime importance to fulfil the environmental objectives of sustainability criteria. The social factor governs the least for selection of sustainable supplementary concrete materials. The nanoparticles of supplementary siliceous material (NPSSM) and fly ash (FA) are the preferred supplementary concrete materials from sustainability consideration.

When the first criterion (technical) weight is interchanged with the second criterion (environmental) weight, i.e., second condition giving highest weight to technical, NPSSM is still the first preference but FA is changed to blast furnace slag (BFS) in the preference of supplementary concrete materials. When the first criterion (technical) weight is interchanged with third criterion (social) weight and with fourth criterion (economic) weight, i.e., third condition giving lower weight to technical, NPSSM and FA will be the preferred supplementary concrete materials and there is no change in the preference of supplementary concrete materials from the original condition. When the second criterion (environmental) weight is interchanged with third criterion (social) weight, i.e., fifth condition, NPSSM is still the first preference but FA is changed to blast furnace slag (BFS) in the preference of supplementary concrete materials. When the first criterion (technical) weight is interchanged with second criterion (environmental) weight, i.e., second condition giving highest weight to technical, NPSSM and Metakaoline (MN) will be the preferred supplementary materials for sustainable concrete. When the second criterion (environmental) weight is interchanged with fourth criterion (economic) weight, i.e., the seventh condition, FA and metakaoline (MN) will be the preferred supplementary materials for sustainable concrete. When the first criterion (technical) weight is interchanged with fourth criteria (economic) weight, i.e., the eighth condition, NPSSM and FA will be the preferred supplementary concrete materials. When the third criterion (social) weight and fourth criterion (economic) weight are interchanged, i.e., ninth giving condition, NPSSM and FA will be the preferred supplementary concrete materials, and there is no change in the preference of supplementary concrete materials from the original condition. The nanoparticles of supplementary siliceous material and fly ash concrete supplementary material are insensitive to the different sustainability objectives and are the most preferred supplementary concrete materials for sustainability. When the economic objectives are assigned a highest weight, the nanoparticles of supplementary siliceous material and fly ash will change its preference to the other supplementary material.

\section{Discussion}

The OSM of supplementary concrete materials with known technical characteristics suggest that engineered materials (nanocement and NPSSM) and industrial wastes materials (BFS, FA, and SF) get a higher score than other supplementary concrete materials. Therefore, these materials will prove to be more technically sound supplementary materials. The results of hybrid AHP-TOPSIS approach, implemented to select the supplementary concrete materials, suggested that among the sustainable indicators to be fulfilled by the construction materials, the environmental indicators should be given priority for the selection of supplementary concrete materials and the socioeconomic indicators are least governing objectives for the selection of supplementary concrete materials. The criteria (sustainable) priority weights obtained by the AHP approach are 0.2559 , $0.4739,0.1154$, and 0.1547 , respectively, for technical, environmental, social, and economic objectives. Among the five shortlisted supplementary concrete materials, nanoparticles of supplementary siliceous material, fly ash, silica fume, metakaolin, and blast furnace slag and the nanoparticles of supplementary siliceous material and fly ash concrete supplementary material are found at the topranked supplementary concrete materials for sustainable development. The closeness coefficient of the five alternatives (supplementary concrete manufacturing materials) obtained by proposed hybrid AHP-TOPSIS approach is $0.268,0.277,0.324,0.164$, and 0.728 , respectively, for blast furnace slag, metakaolin, fly ash, silica fume, and nanoparticles of supplementary siliceous material. The sensitivity analysis shows that the nanoparticles of supplementary siliceous material and fly ash concrete supplementary material are insensitive to the different sustainability objectives and these should be the most preferred supplementary concrete materials for making sustainable concrete manufacturing. It is inferred from the proposed decision support framework that technical sound material will prove to be more sustainable than technical inferior material. Also, the engineered supplementary concrete materials have high sustainable value, and the extra cost incurred on material got 


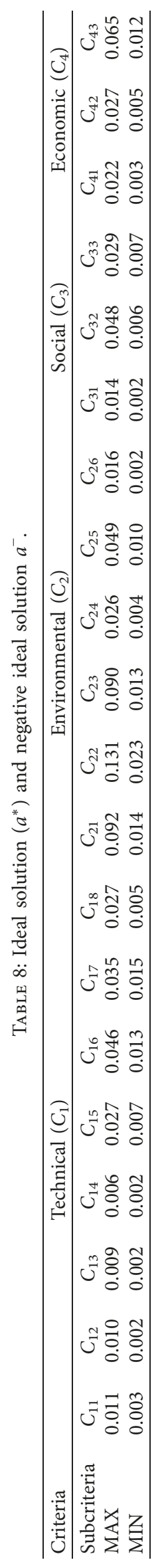


TABLE 9: Final ranking score obtained by TOPSIS.

\begin{tabular}{lcccc}
\hline Material Alternatives & $D_{j}^{*}$ & $D_{j}^{-}$ & CC & Ranking \\
\hline BFS & 0.054 & 0.202 & 0.268 & 4 \\
MN & 0.056 & 0.204 & 0.277 & 3 \\
FA & 0.072 & 0.222 & 0.324 & 2 \\
SF & 0.036 & 0.218 & 0.164 & 5 \\
NPSSM & 0.176 & 0.241 & 0.728 & 1 \\
\hline
\end{tabular}

TABLE 10: Sensitivity analysis output.

\begin{tabular}{lccccccccc}
\hline \multirow{2}{*}{ Condition } & \multicolumn{9}{c}{ Criteria weight } \\
& $W_{1}$ & $W_{2}$ & $W_{3}$ & $W_{4}$ & BFS & MN & FA & SF & NPSSM \\
\hline 1 & 0.2559 & 0.4739 & 0.1154 & 0.1547 & 0.268 & 0.277 & 0.324 & 0.164 \\
2 & 0.4739 & 0.1154 & 0.2559 & 0.1547 & 0.424 & 0.416 & 0.368 & 0.279 & 0.728 \\
3 & 0.1154 & 0.4739 & 0.2559 & 0.1547 & 0.277 & 0.273 & 0.333 & 0.115 & 0.772 \\
4 & 0.1547 & 0.2559 & 0.4739 & 0.1154 & 0.356 & 0.32 & 0.348 & 0.095 & 0.814 \\
5 & 0.2559 & 0.1154 & 0.4739 & 0.1547 & 0.381 & 0.349 & 0.379 & 0.142 \\
6 & 0.4739 & 0.2559 & 0.1154 & 0.1547 & 0.39 & 0.399 & 0.348 & 0.297 & 0.752 \\
7 & 0.2559 & 0.1547 & 0.1154 & 0.4739 & 0.435 & 0.512 & 0.677 & 0.331 & 0.385 \\
8 & 0.1547 & 0.4739 & 0.1154 & 0.2559 & 0.286 & 0.316 & 0.416 & 0.182 & 0.639 \\
9 & 0.2559 & 0.4739 & 0.1547 & 0.1154 & 0.265 & 0.264 & 0.291 & 0.148 & 0.779 \\
\hline
\end{tabular}

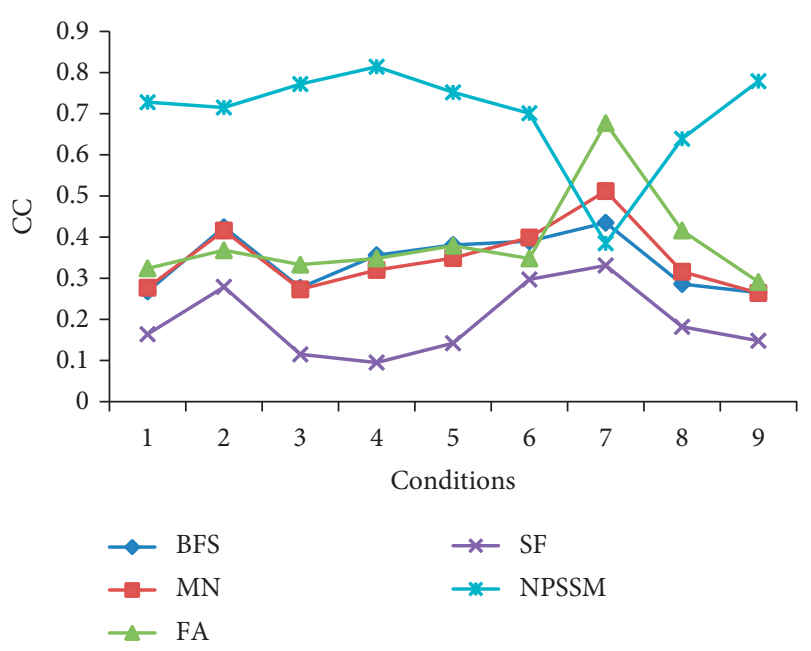

FIGURE 2: Sensitivity analysis with respect to objective (sustainability) criteria.

returned in the form of enhancing material sustainability performance.

\section{Conclusions}

Due to resource scarcity, environmental impact, socioeconomic issues, and resulting global impact, construction industries should implement selection framework for construction material to satisfy the sustainable goals. The concrete manufacturing with proper supplementary materials has the potentiality to satisfy the sustainable objectives. The present study has implemented the integrated OSM and AHP-TOPSIS approach and proposed a decision support framework for sustainable performance assessment of the supplementary concrete materials. The decision framework includes the shortlisting of available supplementary materials, namely, materials from industries by-products, agroproducts, waste products, and new-engineered materials, with known technical characteristics, using the optimal selection method (OSM) approach and ranking of material sustainable potentiality order using the AHP-TOPSIS technique considering performance indicators. The decision support framework considers technical, environmental, social, and economic criteria for the material selection to qualify the supplementary material-added manufactured concrete as sustainable concrete.

It is concluded that among the sustainable goals to be fulfilled by the construction materials, the environmental criteria has to be taken as the priority objective for the selection of supplementary concrete materials and social criteria have the lesser impact for the selection of supplementary concrete materials. It also found from the proposed MCDM approach that the nanoparticles of supplementary siliceous material, i.e., engineered supplementary siliceous material and fly ash, i.e., agriculture-based industrial siliceous waste products are ranked first to provide required sustainability for the concrete manufacturing in the construction industry. The sensitivity analysis shows that the nanoparticles of supplementary siliceous material and fly ash concrete supplementary material are insensitive to the technical, environmental, social objectives, and most sensitive to economic sustainability objectives. The present study thus offers an important contribution by developing integrated OSM-AHP-TOPSIS-based decision model for identifying the sustainable performance concrete material that provides sustainability and boosts the eco-friendly environment [32].

\section{Data Availability}

The data used to support the findings of this study are available from the corresponding author upon request. 


\section{Conflicts of Interest}

The authors declare that there are no conflicts of interest regarding the publication of this paper.

\section{Acknowledgments}

The author acknowledges the Deanship of Scientific Research for providing administrative and financial support. Funding for this work has been provided by the Deanship of Scientific Research, King Khalid University, Ministry of Education, Kingdom of Saudi Arabia, under research grant award number R.G.P.1/82/40.

\section{References}

[1] E. K. Zavadskas, A. Kaklauskas, and J. Saparauskas, "Sustainable urban development and web based multiple criteria analysis," Foundations of Civil and Environmental Engineering, vol. 6, pp. 217-226, 2005.

[2] H. K. Muga, J. W. Betz, C. Pranger, and A. Vidor, Development of Appropriate and Sustainable Construction Materials, Sustainable Futures Institute, Michigan Technological University, Michigan, USA, 2005.

[3] E. Yurdakul, Optimizing Concrete Mixtures with Minimum Cement Content for Performance and Sustainability, Master of Science, Civil Engineering (Civil Engineering Materials), Iowa State University, Ames, Iowa, 2010.

[4] P. Claisse, M. Tyrer, and S. Coupe, "Briefing: how to research and publish new concrete ingredients," Proceedings of the Institution of Civil Engineers-Construction Materials, vol. 163 , no. 2, pp. 57-60, 2010, 2010.

[5] U. G. Y. Abeysundara, S. Babel, and S. Gheewala, "A matrix in life cycle perspective for selecting sustainable materials for buildings in Sri Lanka," Building and Environment, vol. 44, no. 5, pp. 997-1004, 2009.

[6] B. Lothenbach, K. Scrivener, and R. D. Hooton, "Supplementary cementitious materials," Cement and Concrete Research, vol. 41, no. 12, pp. 1244-1256, 2011.

[7] E. S. Bakhoum and D. C. Brown, "Developed sustainable scoring system for structural materials evaluation," Journal of Construction Engineering and Management, vol. 138, no. 1, pp. 110-119, 2012.

[8] E. S. Bakhoum and D. C. Brown, "A hybrid approach using AHP-TOPSIS-entropy methods for sustainable ranking of structural materials," International Journal of Sustainable Engineering, vol. 6, no. 3, pp. 212-224, 2013.

[9] J.-Y. Do and D.-K. Kim, "AHP-based evaluation model for optimal selection process of patching materials for concrete repair: focused on quantitative requirements," International Journal of Concrete Structures and Materials, vol. 6, no. 2, pp. 87-100, 2012.

[10] P. O. Akadiri, P. O. Olomolaiye, and E. A. Chinyio, "Multicriteria evaluation model for the selection of sustainable materials for building projects," Automation in Construction, vol. 30, pp. 113-125, 2013.

[11] A. Ardeshir, N. Mohseni, K. Behzadian, and M. Errington, "Selection of a bridge construction site using fuzzy analytical hierarchy process in geographic information system," Arabian Journal for Science and Engineering, vol. 39, no. 6, pp. 4405-4420, 2014.

[12] P. Arroyo, I. D. Tommelein, and G. Ballard, "Selecting globally sustainable materials: a case study using choosing by advantages," Journal of Construction Engineering and Management, vol. 142, no. 2, 2015.

[13] H. Abdul-Rahman, C. Wang, L. C. Wood, and M. Ebrahimi, "Integrating and ranking sustainability criteria for housing," Proceedings of the Institution of Civil Engineers-Engineering Sustainability, vol. 169, no. 1, pp. 3-30, 2016.

[14] M. Ahmed, M. N. Qureshi, J. Mallick, M. Abul Hasan, and M. Hussain, "Decision support model for design of highperformance concrete mixtures using two-phase AHPTOPSIS approach," Advances in Civil Engineering, vol. 2019, Article ID 1696131, 8 pages, 2019.

[15] C. Favi, E. di Giuseppe, M. D’Orazio, M. Rossi, and M. Germani, "Building retrofit measures and design: a probabilistic approach for LCA," Sustainability, vol. 10, no. 10, p. 3655, 2018.

[16] B. V. V. Reddy and S. S. Lokras, "Steam-cured stabilised soil blocks for masonry construction," Energy and Buildings, vol. 29, no. 1, pp. 29-33, 1998.

[17] de J. Brito, A. S. Pereira, and J. R. Correia, "Mechanical behavior of non-structural concrete made with recycled ceramic aggregates," Cement and Concrete Composites, vol. 27, no. 4, pp. 429-433, 2005.

[18] H. M. Owaid, R. B. Hamid, and M. R. Taha, "A review of sustainable supplementary cementitious materials as an alternative to all-portland cement mortar and concrete," Australian Journal of Basic and Applied Sciences, vol. 6, no. 9, pp. 2887-303, 2012.

[19] V. G. Papadakis and S. Tsimas, "Supplementary cementing materials in concrete," Cement and Concrete Research, vol. 32, no. 10, pp. 1525-1532, 2002.

[20] R. Emmanuel, "Estimating the environmental suitability of wall materials: preliminary results from Sri Lanka," Building and Environment, vol. 39, no. 10, pp. 1253-1261, 2004.

[21] G. Ofori, "Greening the construction supply chain in Singapore," European Journal of Purchasing \& Supply Management, vol. 6, no. 3-4, pp. 195-206, 2006.

[22] M. J. González and J. García Navarro, “Assessment of the decrease of $\mathrm{CO}_{2}$ emissions in the construction field through the selection of materials: practical case study of three houses of low environmental impact," Building and Environment, vol. 41, no. 7, pp. 902-909, 2006.

[23] K. H. Obla, "What is green concrete?," The Indian Concrete Journal, vol. 24, pp. 26-28, 2009.

[24] M. Zimmermann, H.-J. Althaus, and A. Haas, "Benchmarks for sustainable construction," Energy and Buildings, vol. 37, no. 11, pp. 1147-1157, 2005.

[25] S. M. Baharetha, A. A. Al-Hammad, and H. M. Alshuwaikhat, "Towards a unified set of sustainable building materials criteria," in Proceedings of the International Conference on Sustainable Design Engineering and Construction, pp. 7-9, Fort Worth, TX, USA, 2012.

[26] Y. Wang, "Sustainability in construction education," Journal of Professional Issues in Engineering Education and Practice, vol. 135, no. 1, pp. 21-30, 2009.

[27] F. M. González, V. A. P. Salomon, L. G. Ávila, and C. Hernández, "Multicriteria sustainability performance measurement: anp cuban application," in Proceedings of the International Symposium of the Analytic Hierarchy Process 2014, Washington, DC, USA, 2014.

[28] C. Cuadrado, J. M. Zubizarreta, E. Rojí, H. García, and M. Larrauri, "Sustainability-related decision making in industrial buildings: an AHP analysis," Mathematical Problems in Engineering, vol. 2015, Article ID 157129, 13 pages, 2015. 
[29] J. A. Sefair, D. C. Lacouture, and A. L. Medaglia, "Material selection in building construction using optimal scoring method (OSM)," in Proceedings of the Construction Research Congress 2009, pp. 1079-1086, Seattle, WA, USA, April 2009.

[30] T. L. Saaty, "How to make a decision: the analytic hierarchy process," Interfaces, vol. 24, no. 6, pp. 19-43, 1994.

[31] C. L. Hwang and K. Yoon, Multiple Attribute Decision Making Methods and Applications, Springer, New York, NY, USA, 1981.

[32] C. Favi, M. Germani, F. Campi et al., "Life cycle model and metrics in shipbuilding: how to use them in the preliminary design phases," Procedia CIRP, vol. 69, pp. 523-528, 2018. 


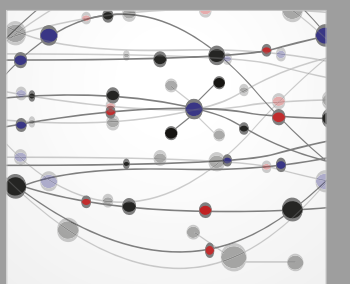

The Scientific World Journal
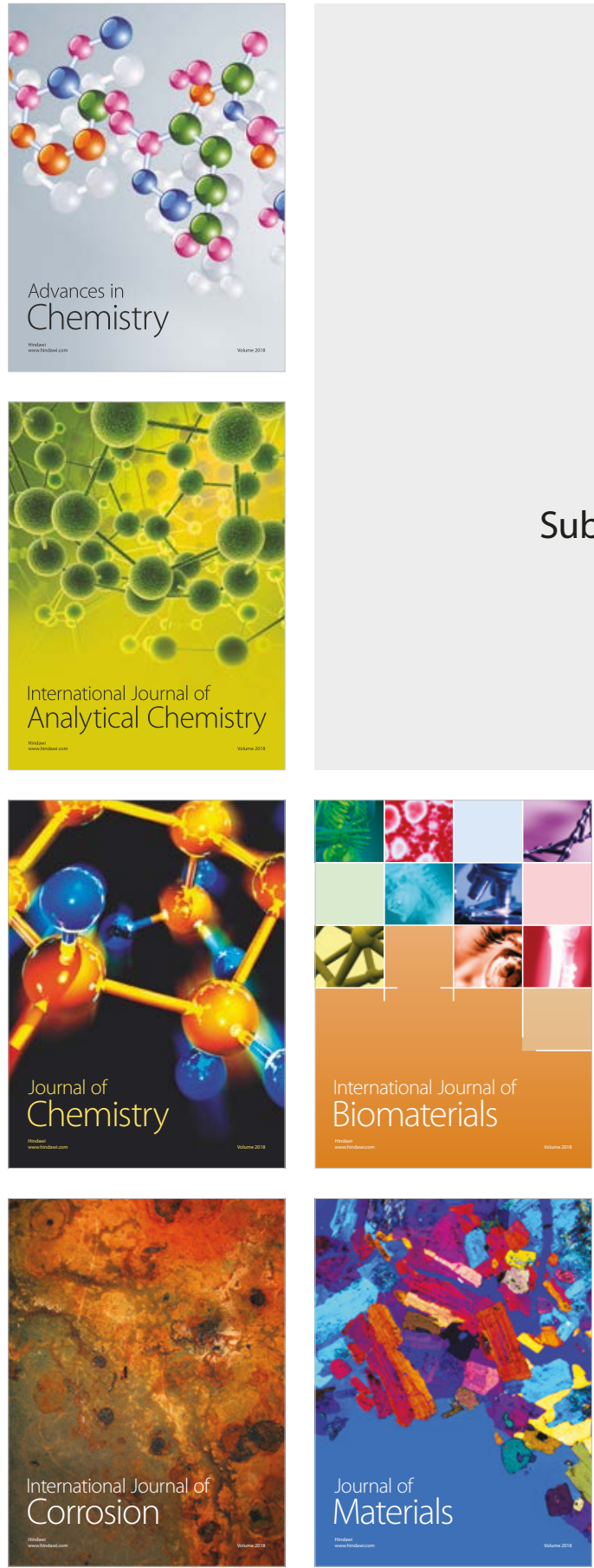

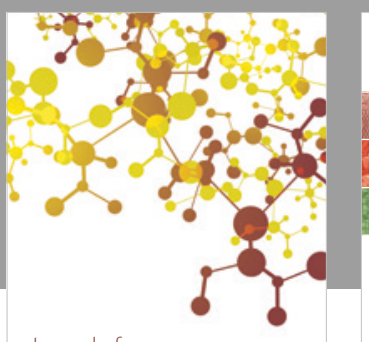

Journal of

Applied Chemistry
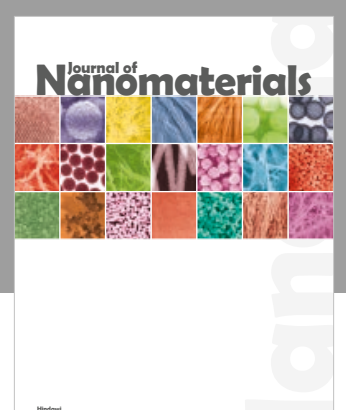

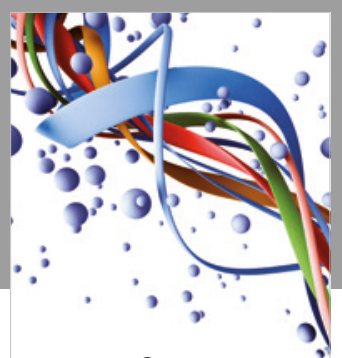

Scientifica

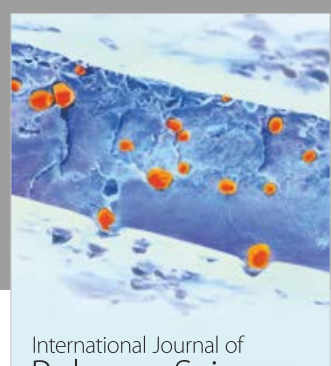

Polymer Science

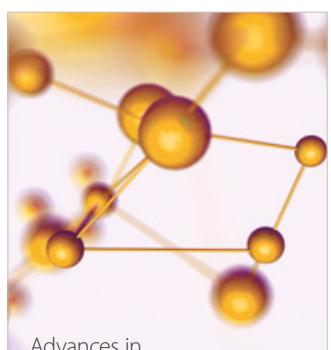

Physical Chemistry
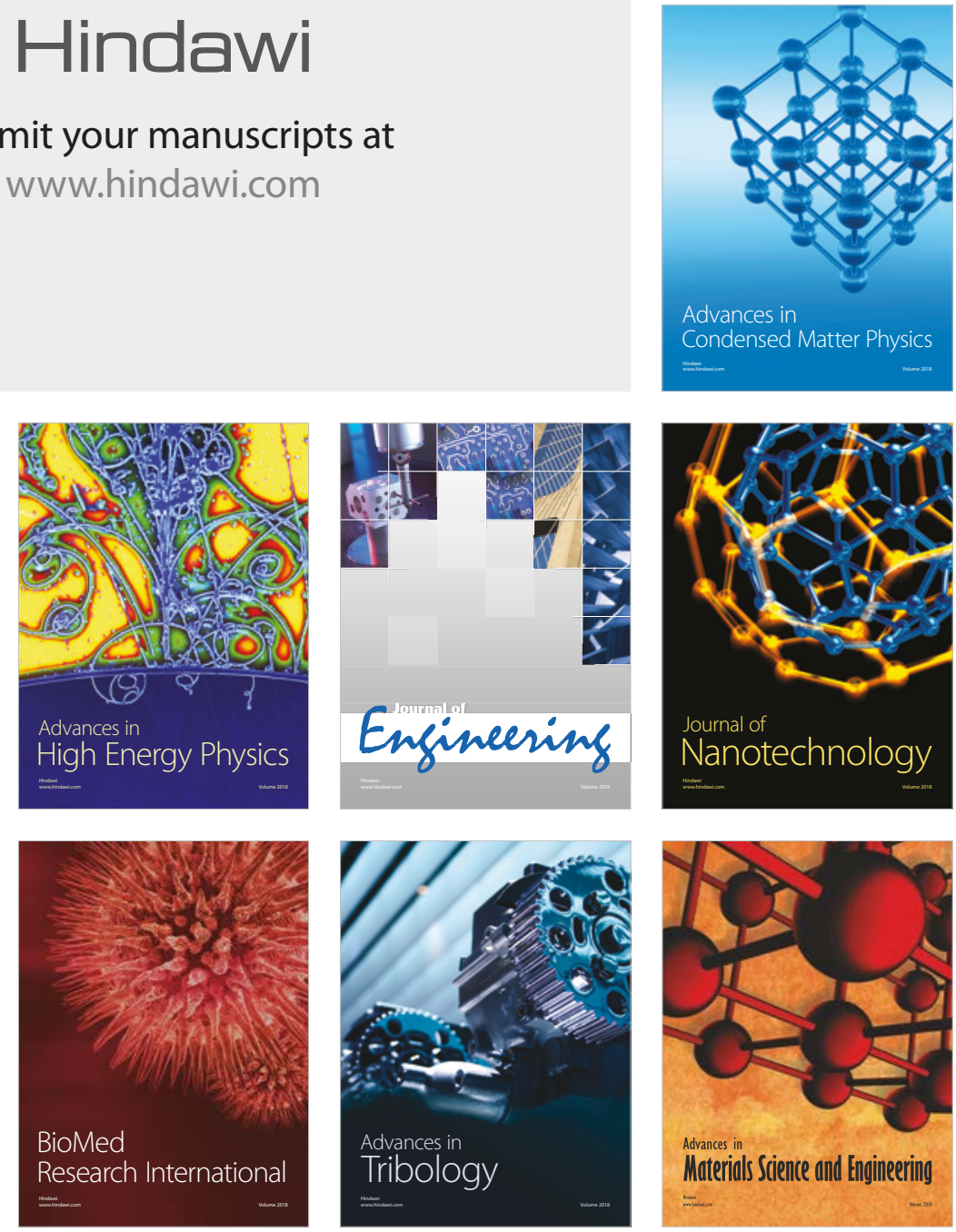